\title{
Synthetic Gene-Based Heterologous Expression, Proteolytic, and Structural Characterization of Caseinolytic Protease of Lactobacillus plantarum IIA-1A5
}

\author{
M. Yusuf*, C. Budiman, I. I. Arief, \& C. Sumantri \\ Department of Animal Production and Technology, Faculty of Animal Science, IPB University \\ Jalan Agatis, Kampus IPB Darmaga Bogor 16680, Indonesia \\ *Corresponding author: m.yusuf08@yahoo.com \\ (Received 05-01-2021; Revised 07-06-2021; Accepted 08-06-2021)
}

\begin{abstract}
Genome sequence of Indonesian probiotic of Lactobacillus plantarum II1A5 contains a gene encoding a proteolytic subunit of caseinolytic protease, designated as ClpP_LP. This study aims to express the Clp gene heterological and apply its proteolytic activity to some livestock products. To address this, the gene encoding ClpP_LP was optimized in silico by improving its Codon Adaptation Index and GC content to 0.94 and $53.62 \%$, respectively. The optimized gene was then inserted into pET28a, transformed into Escherichia coli BL21(DE3), and over-expressed by induction of $1 \mathrm{mM}$ Isopropyl $\beta$-D-1-thiogalactopyranoside at $37^{\circ} \mathrm{C}$. The result showed that ClpP_LP was successfully over-expressed in a fully soluble form with the specific activity towards milk casein was $7739.89 \mathrm{AU}$ $\mathrm{mg}^{-1}$. This activity was significantly greater than that of chymotrypsin. Further, the three-dimensional model of ClpP_LP was built using SWISS MODEL, which showed that this protein formed a homotetradecameric (14-mer) structure with each monomer consisting of $7 \alpha$-helix and $10 \beta$-sheets. The identification of the active side showed that the active side of ClpP_LP is Ser-97, His-122, Asp-171, and forms a substrate-binding cavity with a size of about 29.5 A. Overall, our approach can serve as an appropriate platform for the production of ClpP_LP in a large-scale production for various applications in dairy products and derivatives.
\end{abstract}
Keywords: Clp-Protease; heterologous expression; Lactobacillus plantarum IIA-1A5; structural homology modelling; synthetic gene

\section{INTRODUCTION}

Protease is an enzyme that has the ability to hydrolyze peptide bonds in proteins (Sulthoniyah et al., 2015). This enzyme is widely used by various bio-industries such as detergent making, leather tanning, food processing (Aruna et al., 2014; Miguel et al., 2013), drug manufacture, and biocatalysts in organic synthesis (Nigam, 2013). Protease sales occupy $60 \%$ of total commercial enzyme sales globally and are derived from microorganisms (Singh et al., 2016a). The use of microorganisms as an enzyme-producing source is more beneficial than plants and animals since microorganisms are bred more easily at relatively more affordable costs (Raveendran et al., 2018; Singh et al., 2016b). In addition, the production of enzymes from microorganisms is easier to optimize through regulating conditions of growth and genetic engineering (Gurung et al., 2013).

In general, the production of protease enzymes from bacteria is dominated by non-local bacteria, whereas Indonesia is rich in biodiversity that can act as a source of enzyme-producing microorganisms. Lactic acid bacteria (BAL), including L. plantarum, is one type of bacteria that has the potential as a source of protease. Bacteria L. plantarum IIA-1A5 is a probiotic isolated from fresh beef derived from a traditional market around Bogor, West Java, Indonesia (Arief et al., 2015). Besides being a probiotic, these bacteria can also produce lactic acid and are able to produce bacteriocin plantarisin, which can inhibit the growth of pathogenic bacteria such as E. coli, Salmonella typhimurium, Bacillus cereus, and S. aureus (Arief et al., 2013).

Afiyah et al. (2015) reported that the L. plantarum IIA-1A5 could hydrolyze meat protein from sarcoplasmic and myofibrillar fractions. This capacity is presumably because this strain secreted some proteases which can hydrolyze proteins in the muscles. Budiman et al. (2021) indicated that the genome sequence of this strain harbors some functional genes for foldases and proteases. One protease gene encodes a caseinolytic protease (Clp) which is known to be an essential protease involved in cell division, stress responses, and pathogenicity of bacteria (Frees et al., 2014). The ability of Clp as a proteolytic system is due to the presence of proteolytic subunit (clpP), which belongs to a member of the serine protease family, with the canonical catalytic triad of Ser- 
His-Asp (Florentin et al., 2020). Apart from its cellular function for L. plantarum IIA-1A5, ClpP is promising to be harnessed as a bacterial protease for some applications. Nevertheless, the production of ClpP as a bacterial protease through direct extraction and purification is a considerably lengthy and tedious process. An alternative approach is to utilize recombinant technology, in which the gene is inserted in an appropriate expression vector, transformed into technically and economically affordable host cells (preferably Escherichia coli), overexpressed, and purified. Cardoso et al. (2020) confirmed that recombinant protein production is generally a simple and cost-effective production strategy.

Nevertheless, there is no study for the production of ClpP from L. plantarum group so far. Indeed, no protease from Indonesian LAB was produced through recombinant technology. The production of ClpP of L. plantarum IIA-1A5 is therefore considered a novel recombinant $\mathrm{ClpP}$ produced from $\mathrm{LAB}$. In addition, protein production under recombinant technology is often halted by expression and solubility issues due to the incompatibility of the gene interest, the existence of rare codon, un-ideal GC ratio, or other related issues (Rosano \& Ceccarelli, 2014; Razali et al., 2021). Accordingly, the codon optimization strategy was introduced a few decades ago in which the sequence of gene interest is changed to mimic the codon preferences of the host (Rosano \& Ceccarelli, 2014). This approach was reported to increase the expression of recombinant proteins by more than 1,000-fold (Mauro, 2018).

This study aims to construct the expression system and determine the expressibility of ClpP from L. plantarum IIA-1A5 (ClpP_LP) in E. coli BL21 (DE3) and its ability to degrade protein from livestock products, and predictions of its three-dimensional structure will also be performed. For the construction of the expression system, the gene encoding ClpP_LP was optimized in its codon to meet the ideal condition of E. coli expression. This is, to date, the first ClpP produced from the optimized codon approach and considered a novel approach in the field.

\section{MATERIALS AND METHODS}

\section{Construction and Codon Optimization of ClpP_LP}

The ClpP_LP synthetic gene was designed to be cloned into pET28a (+) expression vector, using two restriction enzymes. This process was carried out by GenScript (New Jersey, USA). The sequence of ClpP_LP gene from the RAST server was then used for the optimization process. The optimization process was carried out using the Optimum ${ }^{\mathrm{TM}}$ system from GenScript (New Jersey, USA). The optimization process was directed to three parameters: codon adaptation index (CAI), GC content, and frequency of codon usage (FOC). The optimized genes were then synthesized chemically and inserted into the pET28a (+) plasmid expression vector (Novagen) using Nde1 and Bam $\mathrm{H} 1$ restriction enzymes. E. coli host cells BL21 (DE3) were used for recombinant protein production. Recombinant plasmids were cut by two restriction enzymes Mlu1 (A ICGCGT) and BamH1
(GIGATC C), to evaluate the success of target DNA insertion in the pET28a $(+)$ plasmid. Restriction fragments were then observed using an agarose gel.

\section{Transformation of Recombinant Plasmids and Screening of Positive Transformants}

The transformation of recombinant plasmids was performed according to the methods previously described by Murwantoko et al. (2016) and Rahimzadeh et al. (2016). A total of $5 \mu \mathrm{L}$ recombinant plasmids DNA was dissolved in $100 \mu \mathrm{L}$ of a competent cell suspension then homogenized. The mixture was incubated in the ice for $30 \mathrm{~min}$, then heat-shocked at $42^{\circ} \mathrm{C}$ for 90 seconds using heat block, then placed back in ice for $30 \mathrm{~min}$ and incubated at $37^{\circ} \mathrm{C}$ for 1 hour by adding $1 \mathrm{~mL}$ of LB medium (without antibiotics). After 1 hour, $0.3 \mathrm{~mL}$ of the transformed cells were cultured in LB medium containing kanamycin antibiotics $(35 \mu \mathrm{g} / \mathrm{mL})$ to select positive transformants. The positive transformants were used for further expression experiments.

\section{Heterologous Expression of ClpP_LP in E. coli BL21 (DE3)}

The recombinant plasmids (pET28a_ClpP_LP) were expressed in E. coli BL21 (DE3) according to the method described by Kang et al. (2015). Recombinant E. coli were cultured in $5 \mathrm{~mL}$ of LB (Luria Bertani) broth medium at $37^{\circ} \mathrm{C}$ containing kanamycin antibiotics at the final concentration of $35 \mu \mathrm{g} / \mathrm{mL}$ overnight. The culture was transferred in a larger new medium $(250 \mathrm{~mL})$ containing kanamycin antibiotics at the final concentration of $35 \mu \mathrm{g} / \mathrm{mL}$ and incubated with a water-bath shaker at $37^{\circ} \mathrm{C}$ for 1 hour. The protein expression was induced by isopropyl-D-1-thiogalactopyranoside (IPTG) at the final concentration of $1 \mathrm{mM}$. The culture was further incubated at $37^{\circ} \mathrm{C}$ for 5 hours, and every 1 hour, as much as $50 \mathrm{~mL}$ of the culture was harvested. The cells were harvested by centrifugation at 13,000 rpm for 5 minutes at $4^{\circ} \mathrm{C}$. The cell pellets were dissolved into a lysis buffer $(10 \mathrm{mM}$ Tris- $\mathrm{HCl}, \mathrm{pH} 7.5)$ and were sonicated at 30 $\mathrm{kHz}$ amplitude for $30 \mathrm{~min}$. Centrifugation at 13,000 rpm was used to separate between cell-free supernatant and insoluble protein aggregates. The resulting supernatant (soluble protein) and precipitate (insoluble/aggregated proteins) were analyzed by $15 \%$ SDS-PAGE.

\section{Analysis of Expression of Heterologous Proteins by SDS-PAGE}

SDS-PAGE also analyzed the expression of the recombinant plasmids to validate the molecular weight of the protein produced following the procedure described by Fatmarani et al. (2018). The concentration of polyacrylamide used was $15 \%$ for the resolving gel and $5 \%$ for the stacking gel. Each sample $(100 \mu \mathrm{L})$ was mixed with $200 \mu \mathrm{L}$ of sample buffer and heated for 4 $\min$ at $95^{\circ} \mathrm{C}$. Electrophoresis was performed with Mini Protean (Bio-Rad) at $120 \mathrm{~V}$ until the bromophenol blue marker reached the bottom of the gel (about $45 \mathrm{~min}$ ). The gels were then stained for 40 minutes in $0.1 \%(\mathrm{w} / \mathrm{v})$ 
Coomassie Brilliant Blue R-250 (Sigma, St. Louis, MO, USA) in methanol: acetic acid: water (40: 10: 50) and then de-stained in methanol: acetic acid: distilled water (10: 10: 80) for 24 hours.

\section{Measurement of Protein Concentration}

Proteins were analyzed based on the method described by Fatmarani et al. (2018). Each sample of 100 $\mu \mathrm{L}$ was homogenized with $3.9 \mathrm{~mL}$ of distilled water, and then $5.5 \mathrm{~mL}$ of reagent $\mathrm{A}$ containing $0.1 \mathrm{~N} \mathrm{NaOH}$; $2 \% \mathrm{Na}_{2} \mathrm{CO}_{3} ; \mathrm{CUSO}_{4} 0.5 \%$; and Tartat $1 \%$ was added. The mixture was then homogenized and allowed to stand for 15 minutes at room temperature (RT). The mixture of reagent B was added (folin-ciocalteu, 1:10) as much as $0.5 \mathrm{~mL}$, then stirred immediately and allowed to stand for 30 minutes until the sample was blue. The concentration of protein was measured by spectrophotometer at a wavelength $\lambda=650 \mathrm{~nm}$. Bovine Serum Albumin (BSA) was diluted sequentially with a concentration of 0.25 $\mathrm{mg} / \mathrm{mL}$, and it was used as the standard.

\section{Analysis of Proteolytic Activity}

The analysis of proteolytic activity was carried out by the good diffusion method according to Rohin et al. (2012) with modifications. The extract of crude protease enzyme was put in sterile petri dishes containing LB medium that was enriched with $5 \%$ of specific substrate (milk and meat protein). A total of $60 \mu \mathrm{L}$ of crude enzyme extract was dispensed in wells bored in the agar plates, then incubated at $37^{\circ} \mathrm{C}$. Proteolytic activity is indicated by a clear visible zone around the wellbore. Furthermore, proteolytic activity was calculated by measuring the diameter of the clear area formed by using calipers and expressed as a protein-specific activity (AU $\left.\mathrm{mg}^{-1}\right)$.

\section{Homology Modelling and Model Evaluation}

The three-dimensional (3D) structure of ClpP_LP was constructed using the homology modeling method according to the method described by Waterhouse et al. (2018). SWISS-MODEL server (http://swissmodel. expasy.org/) was used for the ClpP_LP structure prediction. SWISS-MODEL is automatically equipped with a template selection feature by searching in parallel the best templates with BLAST (Camacho et al., 2009) and Hhblits (Remmert et al., 2011; Bienert et al., 2017).

The protein model obtained was then evaluated by GMQE (Biasini et al., 2014), QMEAN, and PROCHECK (Haddad et al., 2020). GMQE is a quality estimation that combines properties from the target-template alignment and the template search method. QMEAN was used to evaluate the model based on different geometrical properties and provides both local (per residue) and global (for the entire structure) absolute quality estimates of different regions within the model (Haddad et al., 2020). PROCHECK (Ramachandran plot) was used to analyze the stereochemical and overall quality of the structure (Shin et al., 2017).

\section{RESULTS}

\section{Codon Optimization and Cloning of ClpP_LP}

The Codon sequence of ClpP_LP was analyzed using the Optimum ${ }^{\mathrm{TM}}$ system from GenScript (New Jersey, USA) (Figure 1). The result showed that its GC content was $48.08 \%$, with CAI of 0.51 . Furthermore, the codons were optimized to match the E. coli codon preference. The result of optimization showed an increase of GC content to $53.62 \%$ with CAI of 0.93 .

The validation of recombinant plasmid was performed with $1 \%$ agarose gel electrophoresis. Double digest with restriction enzymes Mlu1 and BamH1 on the recombinant plasmid yielded two DNA fragments. Figure 1 showed the presence of the inserted gene of $\mathrm{ClpP}$ in the expression system. The target gene was 591 $\mathrm{bp}$, in its size. However, as the inserted check used MIuI and BamHI, the digestion product had an accumulative size of about 1,500 bp. Figure 2(b), Lane 2, with the size of about $4500 \mathrm{bp}$ showed two obvious bands with the apparent sizes of about 4500 and $1500 \mathrm{bp}$, which corresponded to the digested pET28a and ClpP_LP gene (with the addition of $M l u \mathrm{I}$ and $\mathrm{BamHI}$ fragments with the size of about $1000 \mathrm{bp}$ ). This confirmed that the recombinant plasmid indeed contained the inserted ClpP_LP gene. Meanwhile, the undigested recombinant plasmids showed multiples bands with apparent sizes in the range of 4000-6000 bp (Figure 2(b), Lane 1). This was due to the possible conformation of the plasmid in either supercoiled or open-circular. Under this conformation, the apparent size of the recombinant plasmid did not reflect its true size.

\section{Screening of Positive Transformants}

The recombinant plasmids were expressed in the host cell of E. coli BL21 (DE3). Screening of positive transformants was done to ensure that the cell successfully captured the recombinant plasmids. The screening was done by growing E. coli in an LB medium containing kanamycin antibiotics of $35 \mu \mathrm{g} / \mathrm{mL}$ because plasmid pET28a $(+)$ was equipped with a marker selection of genes that were resistant to kanamycin antibiotics. The positive transformant will grow to form colonies, as shown in Figure 3. Colonies that grew in media that have been added to kanamycin antibiotics were then collected and stored in the form of glycerol stock for further expression analysis.

\section{Analysis of Expression of Heterologous Proteins by SDS-PAGE}

The results showed that adding isopropyl-D1-thiogalactopyranoside (IPTG) as an inducer in a final concentration of $1 \mathrm{mM}$ was successful in expressing the heterologous proteins in E. coli Bl21 cell hosts. In this study, E. coli Bl21 (DE3) was able to express the ClpP_LP at 5-hour induction as indicated by the presence of a new band that appeared only after IPTG induction (Figure 4A). In addition, the band only appeared in the soluble fraction, which indicated that ClpP_LP was 
(a)

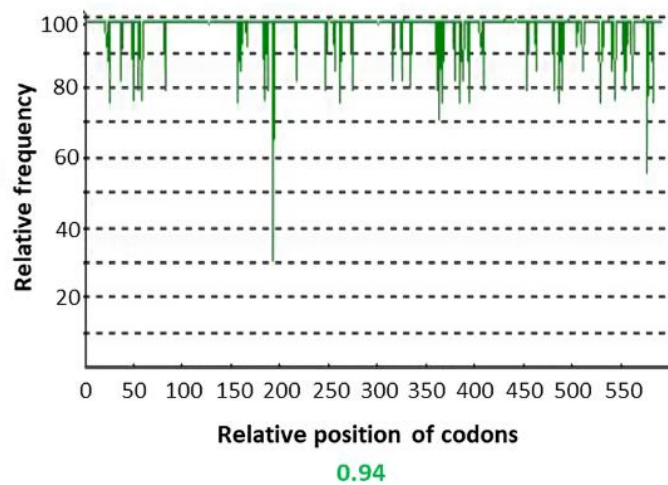

(c)



(b)

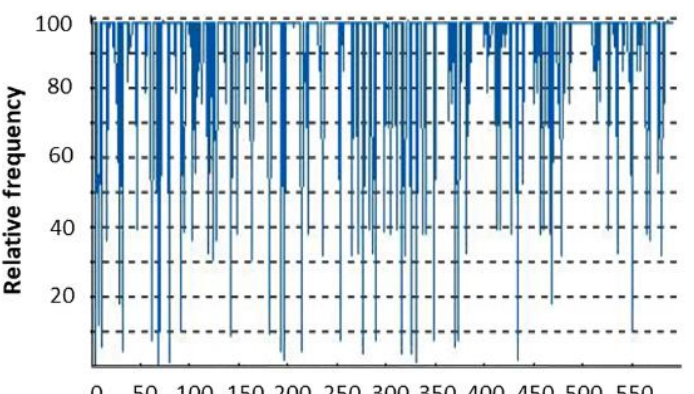

$0 \quad 50100150200250300350400450500550$

Relative position of codons

CAI:
0.51

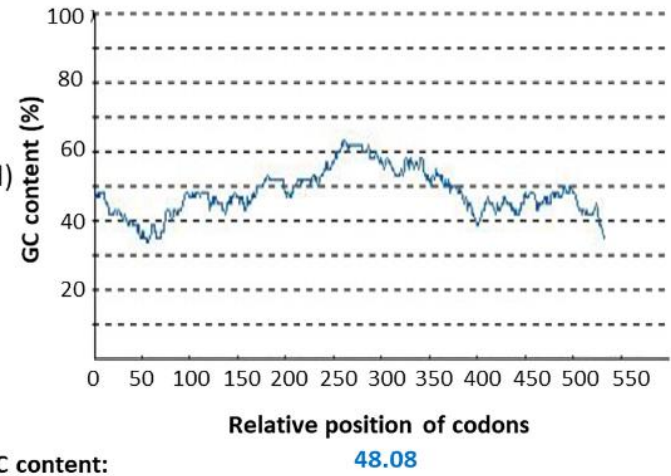

Figure 1. The value of Codon Adaptation Index (CAI) and GC content of ClpP_LP. (a) CAI after optimization, (b) CAI before optimization, (c) GC content after optimization, and (d) GC content before optimization.

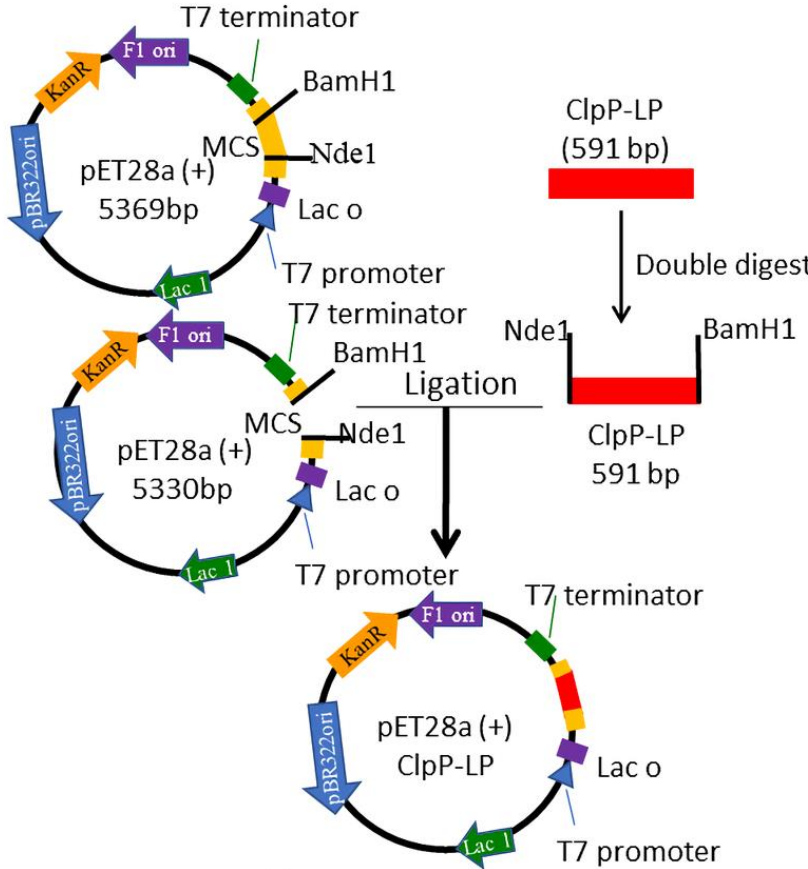

(a)

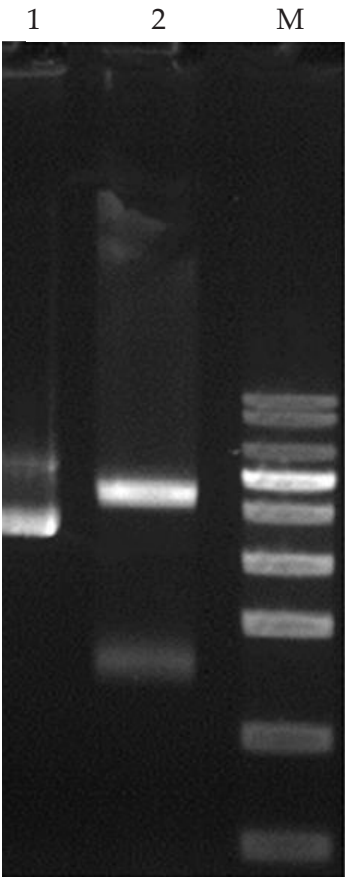

(b)

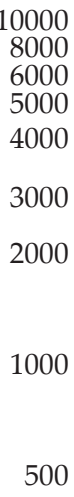

500

Figure 2. Construction of pET28a_ClpP_LP (a), Restriction analysis of recombinant plasmids by using 1\% agarose gel electrophoresis (b). Line 1 is a non-digesting recombinant plasmid, line 2 is a recombinant plasmid digest with $\mathrm{Mul1}$ and Bam $\mathrm{H1}$, line $\mathrm{M}$ is a KB Ladder marker.

expressed in a fully soluble form. To note, Figure 4A indicated that ClpP_LP appeared as a double band on the SDS-PAGE, in which the upper and lower bands have relative mobility (Rf) in the gel of 0.55 and 0.56 , respectively. Calculation of the apparent molecular sizes of the band of ClpP_LP based on the Rf values revealed that both bands had similar sizes $25 \mathrm{kDa}$ (upper band) and $24.1 \mathrm{kDa}$ (lower band). These sizes were slightly larger than the theoretical size of ClpP_LP, which was calculated based on its amino acid sequence (23.2 kDa). 
However, this small difference is acceptable and often happens due to the unique behavior of proteins during migration in the gel.

\section{Protein Specific Activity}

The analysis showed that the specific activity of ClpP_LP protein was higher than chymotrypsin and E. Coli (Figure 5). On the other hand, ClpP_LP and chymotrypsin also showed a trend of increasing proteinspecific activity along with incubation time. In this study, the control treatment with $E$. coli extracts without the ClpP_LP gene showed no specific protein activity. This meant that the specific protein activity of ClpP_LP purely came from the ClpP_LP encoding gene.

\section{Homology Modelling and Model Evaluation}

The target sequence of ClpP_LP with 196 amino acids was retrieved from the Rapid Annotation using Subsystem Technology (RAST) Annotation Server. The structure was modeled using SWISS-MODEL on the web at http://swissmodel.expasy.org. The struc-

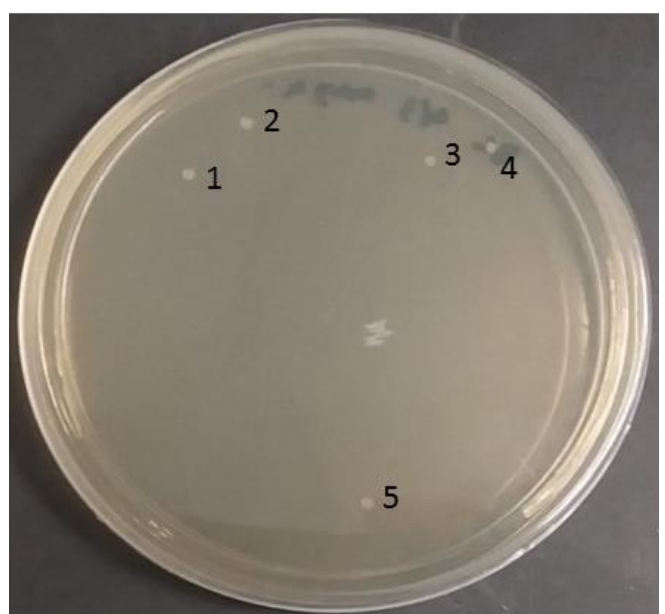

Figure 3. Screening of E. coli Bl21 (DE3) harboring recombinant protease gene onto LB agar plates containing kanamycin antibiotics $(35 \mu \mathrm{g} / \mathrm{mL})$. tural evaluation and stereo-chemical analysis of the selected model were performed using QMEAN and PROCHECK, respectively. The identification of the template using BLAST and HHblits has been performed against the SWISS-MODEL template library, which produced as many as 638 templates. The results of template identification produced the best template in the form of 3TT7 protein (Figure 6). The selection of the best template structure was based not only on the similarity of the sequence but also on other factors such as experimental quality, bound substrate molecules, or different template conformations (Waterhouse et al., 2018).

Evaluation of the protein model showed that the average QMEAN (Qualitative Model Energy Analysis) model was 0.92 , which was generally greater than the minimum QMEAN value for a structure model. This indicated that the model was of good structure and acceptable. The Ramachandran plot generated by PROCHECK showed $94.2 \%$ amino acids were in the favored region, and $0.3 \%$ were in the outlier region based on Phi and Psi angles (Figure 7). Altogether, nearly $100 \%$ of the residues were in the favored and allowed regions indicating that the protein model was good.

\section{The ClpP_LP Active Side Analysis and Substrate Cutting}

The analysis of the active side of ClpP_LP was carried out by aligning the amino acid constituents of ClpP_LP with the template protein (3TT7) and Clp from several different bacteria whose active side was previously known. The results of ClpP_LP alignment by Clustal Omega showed that the active side of ClpP_LP consisted of three amino acids (triad catalytic). The triad catalytic of ClpP_LP was located in the Ser97, His122, and Asp171 (Figure 10). The homo tetradecameric structure of ClpP_LP formed a barrel-like structure that had two tunnels opening (top and bottom) for entry of protein and exit of the products (Figure 11). The measurement of the diameter of the tunnel in the ClpP_LP homo-heptameric structure was $29.5 \AA$. This size was considered for several types of proteins substrate to be degraded by these proteases in the cells.
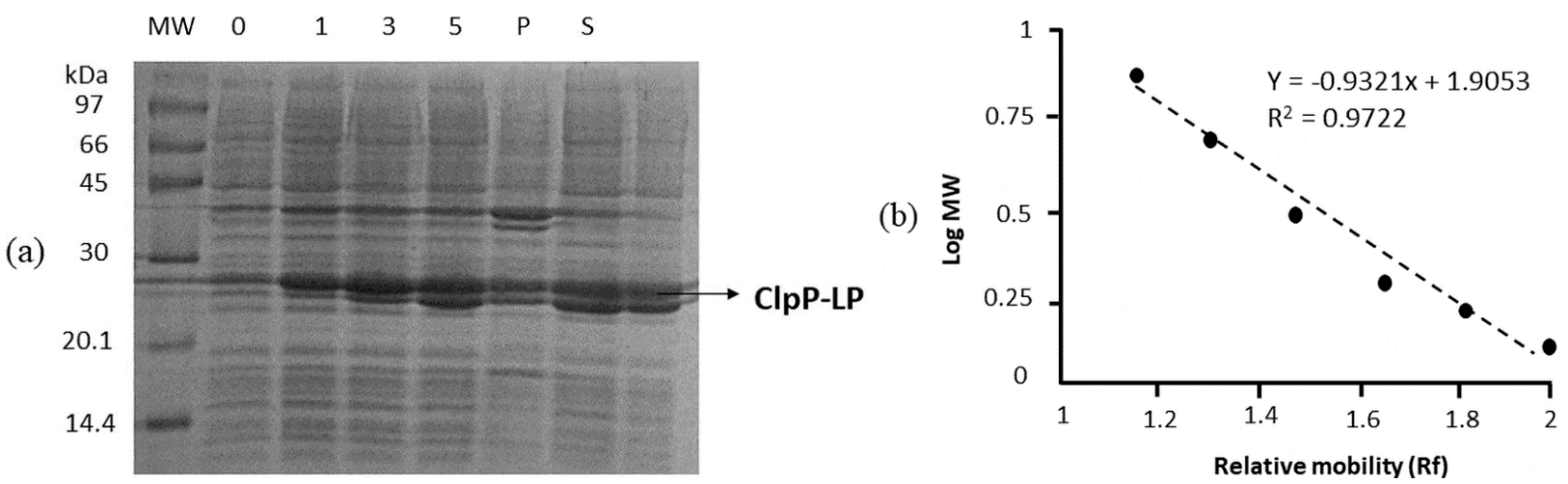

Figure 4. (a). Expression profile of ClpP_LP under SDS-PAGE. MW is a marker. Lane 0 is E. coli BL21(DE3) without IPTG induction. Lanes 1, 3, and 5 correspond to E. coli BL21(DE3) after being induced by IPTG for 1, 3, and 5 hours. Lanes P and S correspond to pellet and soluble fractions of the 5-hour induced E. coli BL21(DE3) after being lysed. (b). Relationship of the relative mobility (Rf) and molecular weight of protein markers derived from SDS-PAGE. The linear equation was used for the calculation of apparent size of ClpP_LP from SDS-PAGE. 


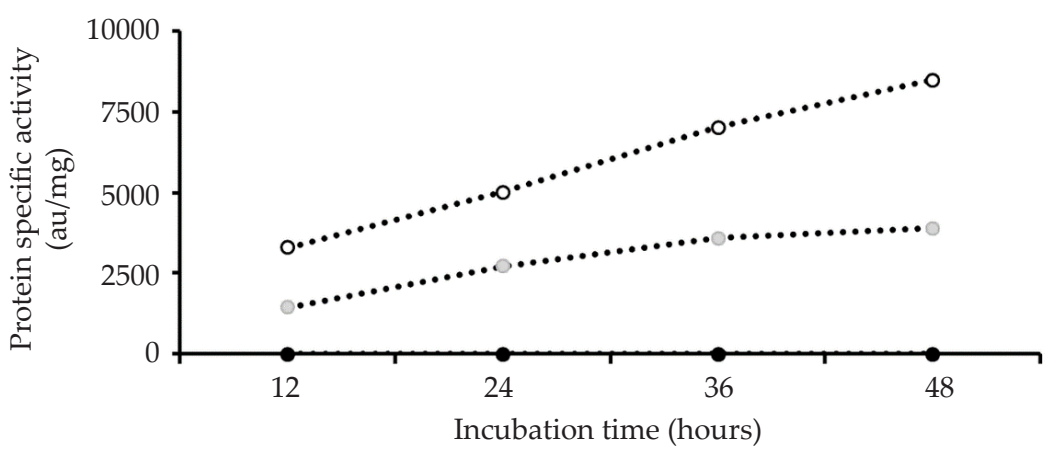

Figure 5. Specific activity of ClpP_LP protein in LB medium containing 5\% skim milk; ClpP_LP (......), Chymotrypsin $(\ldots \odot \ldots)$, Protein extract of E. coli $(\ldots \bullet \ldots)$.

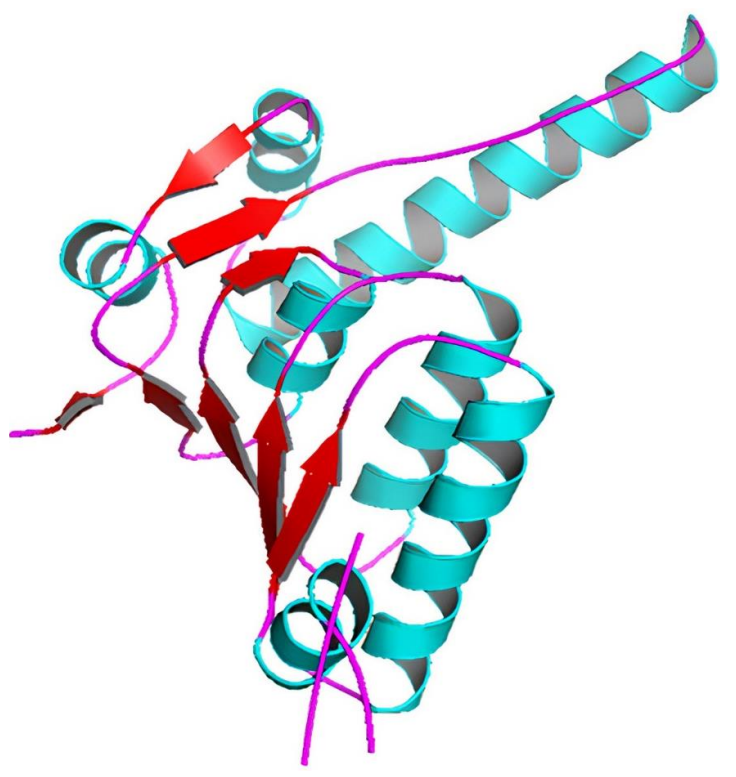

Figure 6. Three-dimensional structure of the 3TT7 template protein

\section{DISCUSSION}

In this study, the expression level of the optimization of genes synthesis is quite good because it has a CAI value greater than 0.8 . The GC content of the ClpP_LP recombinant genes is also quite good, where the percentage of GC ideally ranges from $30 \%-70 \%$. The Codon Adaptation Index (CAI) is the primary index used to predict gene expression levels of heterologous proteins (Fu et al., 2020), with the highest values being 1.0 and CAI values above 0.8 being good. Heterologous proteins will not be expressed as well if the target gene is found in many rare codons used in the host cells. It also induces a strong host cell metabolic burden (Rahmen et al., 2015).

Codon optimization through the in-silico method is a common strategy to increase the expression of heterologous proteins without changing the amino acid sequence of the encoded protein (Gaspar et al., 2012). The in silico (bioinformatics) method is a computational-based analysis method combined with mathematical,

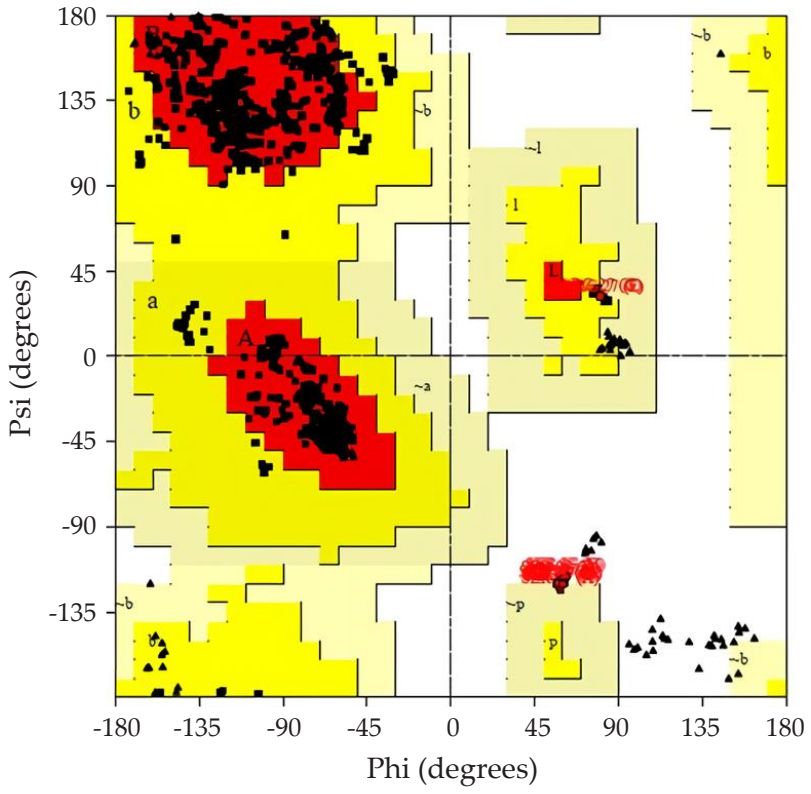

Figure 7. Ramachandran plot of ClpP_LP obtained through the modelling

chemical, and biological algorithms to predict and analyze a protein's structure and activity (Kuhlman \& Bradely, 2019). The application of this technology has been utilized to generate recombinant proteins for use in pharmaceuticals (Liu et al., 2018). It is more effective and efficient than direct gene isolation and can prevent disease transmission (Hughes et al., 2011). In addition, the in-silico approach can save time and costs needed in a study (Yaraguppi et al., 2012).

The cloning strategy was depicted in Figure 2 (a). In this study, restriction enzymes used were Nde1 and BamH1, and both enzymes can be recognized restriction sites in the Multiple Cloning Site (MCS) of plasmid pET28a (+). The Nde1 restriction enzyme cuts the DNA fragment in the $5^{\prime}$-CA $\downarrow$ TATG-3' sequence and its complement $3^{\prime}-\mathrm{GTAT} \downarrow \mathrm{AC}-5^{\prime}$ (Watson et al., 1982), meanwhile the restriction enzyme $B a m \mathrm{H} 1$ intersects the DNA fragment in the 5'-G $\downarrow$ GGATCC-3' sequence and its complement of $3^{\prime}-\mathrm{CCTAG} \downarrow \mathrm{G}-5^{\prime}$ (Newman et al., 1994). Plasmid and synthesis DNA cutting with both enzymes will produce a fragment with complementary 




Figure 8. The predicted model of ClpP_LP in the forms of barrel-shaped homo-heptameric. The red structure indicates protein monomer.

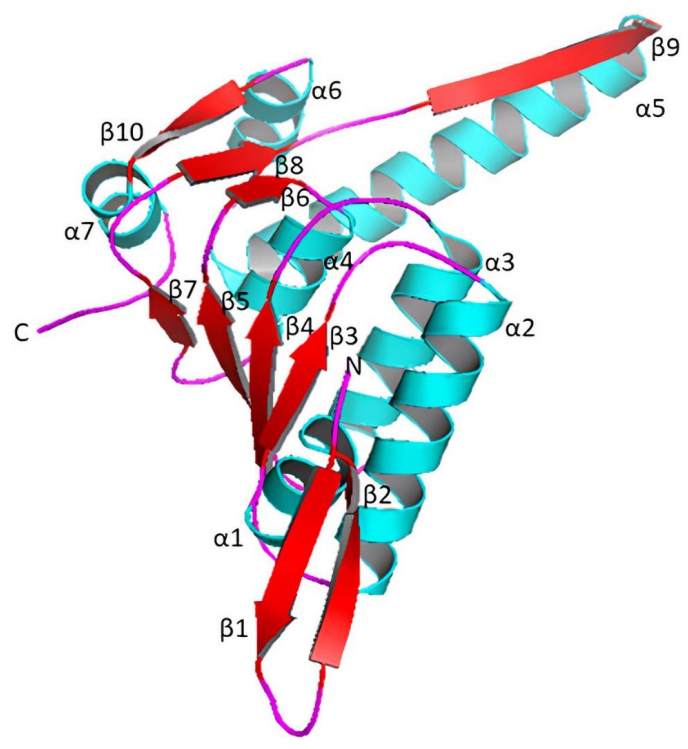

Figure 9. ClpP_LP monomer is dominated by $\beta$-sheet structures. Each of the structure identified and labeled as $\alpha$-helix and $\beta$-sheet. Both of N-terminal and C-terminal labeled as $\mathrm{N}$ and $\mathrm{C}$, respectively.
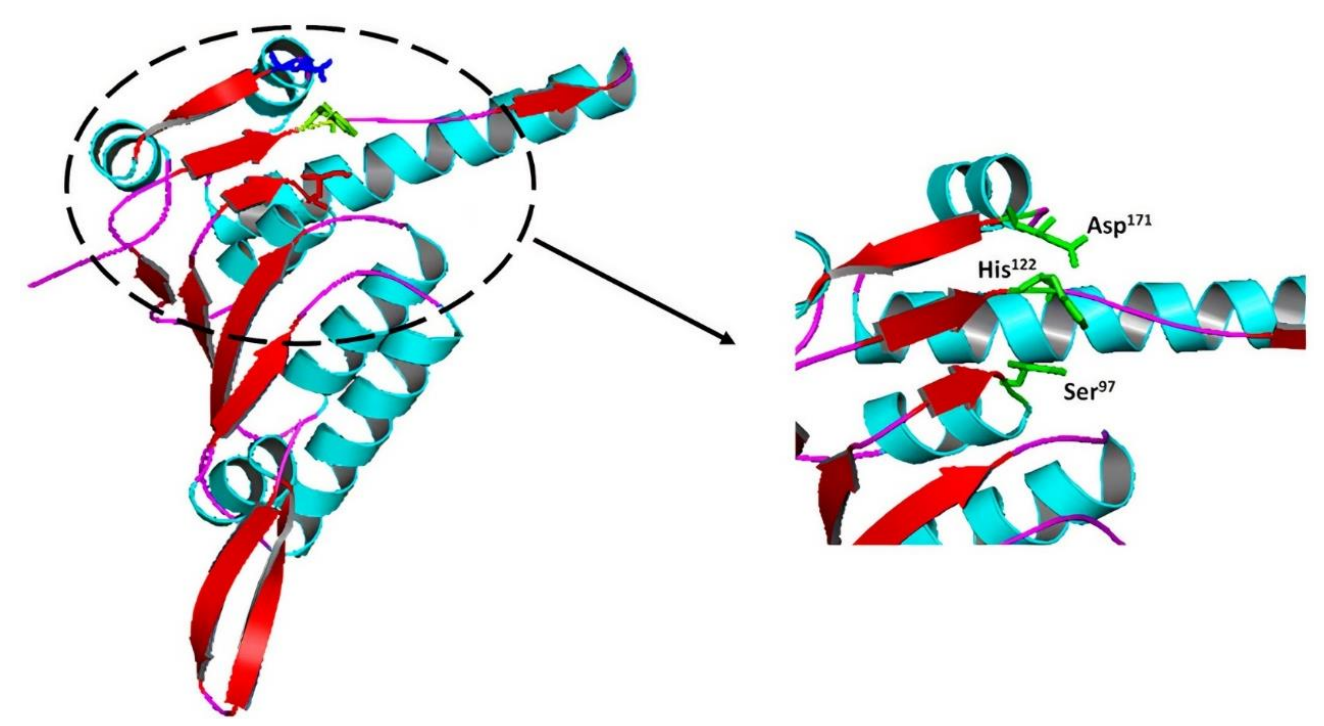

Figure 10. The residues catalytic triad in ClpP_LP. The black circle indicates the position substrate binding to the catalytic triads.

sticky tips so that DNA can be inserted into the plasmid to form a relatively stable hydrogen bond. Sticky ends are unpaired nucleotides at the ends of DNA molecules that can associate to link DNA segments with a plasmid (Ban \& Picu, 2013). It will also facilitate the performance of ligase enzymes in connecting DNA with plasmids through phosphodiester bonds.

The success of heterologous proteins expression was influenced by many factors such as the good expression vector choice, the suitable cell hosts, using induction, time of induction, and codon optimization. In this study, we used the pET28a (+) (Novagen) as the expression vector. The $\mathrm{pET}$ expression system is based on the T7 promoter of T7 bacteriophage that is common for recombinant proteins expression (Fiege \& Dinkel, 2020).
In this system, the gene of interest is cloned behind a promoter recognized by the phage T7 RNA polymerase (T7 RNAP), so that is why we use E. coli BL21 (DE3) as a cell host. The concentration of inducer used plays an important role in the expression process where the use of inducers in low concentrations causes inefficient induction, whereas if using high concentrations can also cause toxic effects that inhibit the growth of the host cells (Ramirez et al., 1994; Browning et al., 2019). However, low concentrations are more beneficial because they will reduce the cost of producing these proteins. In this study, a concentration of $1 \mathrm{mM}$ IPTG is enough to induce the expression of these genes. This concentration is considered normal because many recombinant proteins are expressed using IPTG at this concentration. 


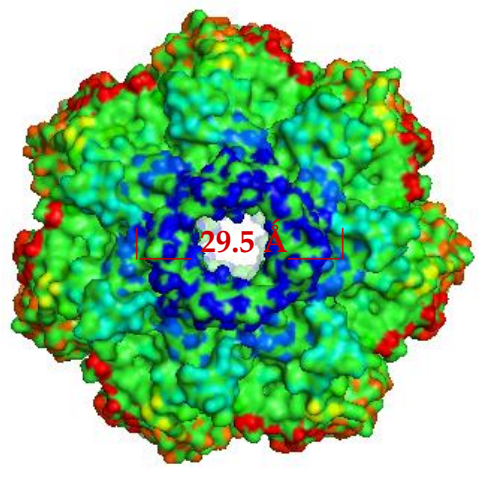

(a)

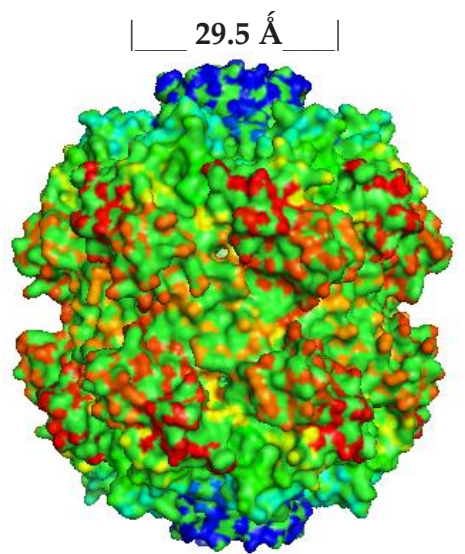

(b)

Figure 11. Three-dimensional structure of 14-mer ClpP_LP. It shows the upper view (a) and side view (b) of the homo-heptameric ClpP_LP.

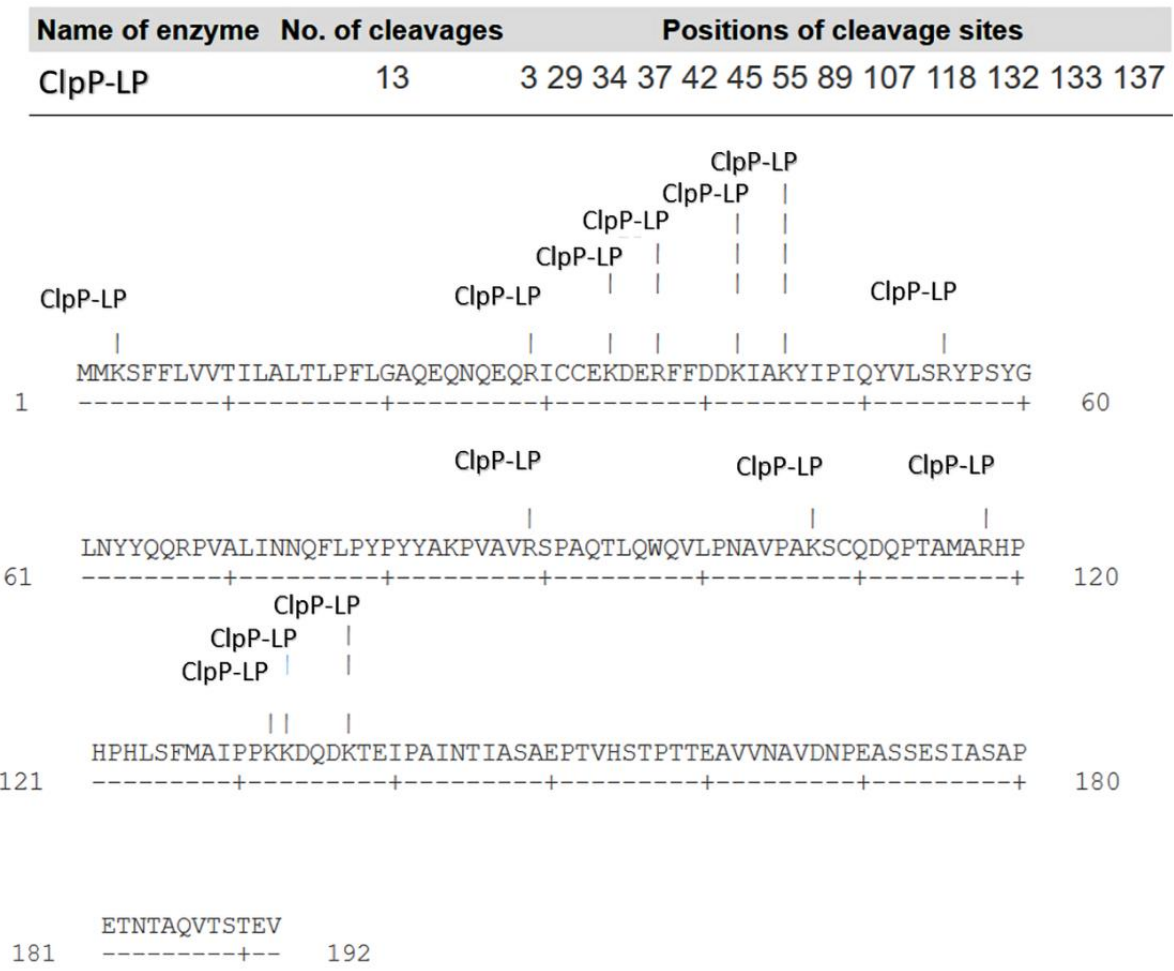

Figure 12. Map of ClpP_LP cutting in sequences of casein

In this study, the specific activity of proteins from ClpP_LP was better than control because skim milk contained a lot of casein protein, a specific substrate of ClpP_LP. Casein is the major protein in milk, divided into $\alpha-, \beta$ - and $\kappa$-casein (Rehan et al., 2019). To note, casein is known to be the natural substrate for ClpP, which is therefore named as 'caseinolytic' protease. Nevertheless, the structural homology modeling indicates that the tunnel diameter of ClpP_LP is smaller than the micelle structure of casein $(50-500 \mathrm{~nm})$. Accordingly, it is not possible for ClpP_LP to degrade casein in its micelle-like structures due to size constrain. It is, therefore, proposed that ClpP_LP accommodates casein in its sub-micelle structure. Previously, crude protein extract of L. plantarum IIA-1A5 showed the ability to degrade myofibrillar proteins and sarcoplasmic meat (Afiyah et al., 2015). This nevertheless remains to be confirmed whether the ability is modulated by ClpP_LP or other proteases of this strain.

The model generated by SWISS-MODEL server used ClpP of Bacillus subtilis (PDB ID: 3TT7), which was obtained from X-ray diffraction at $2.56 \AA$ (Lee et al., 2011). The template showed a sequence identity of $65.13 \%$ with ClpP_LP, with coverage of $99 \%$. The value of sequence identity between the target protein and the template is the first assessment that must be done on 
the quality of the model (Bordoli et al., 2009). Overall, ClpP of Bacillus subtilis is considered as an acceptable template for structural modeling of ClpP_LP.

The prediction model of the target protein (ClpP_LP) using the SWISS-MODEL server produced a three-dimensional (3D) structure of the target protein, as was described in Figure 8. This protein model also showed the possibility of this protein forming an oligomeric structure composed of 14 identical protein monomers (homo-tetradecameric). The model showed that ClpP_LP was in the form of a barrel, which was the same as the 3TT7 template protein (Lee et al., 2011). The structure of ClpP resembles a barrel, where the protein that will be degraded first is translocated into a protease and will be released in the form of chopped amino acids.

The monomer of ClpP_LP is dominated by the $\beta$-sheet structures (Figure 9). Seven $\alpha$-helixes were found in this protease. The first $\alpha$-helix was extended from amino acid of $\mathrm{I}_{19}$ to $\mathrm{D}_{26}$, the second $\alpha$-helix was extended from amino acid of $\mathrm{D}_{37}$ to $\mathrm{Q}_{53^{\prime}}$ the third $\alpha$-helix was extended from amino acid of $\mathrm{I}_{70}$ to $\mathrm{F}_{82^{\prime}}$ the fourth $\alpha$-helix was extended from the amino acid of $M_{98}$ to $G_{105^{\prime}}$ the fifth $\alpha$-helix was extended from amino acid of $\mathrm{Q}_{132}$ to $\mathrm{T}_{157}$, the sixth $\alpha$-helix was extended from amino acid of $\mathrm{I}_{161}$ to $\mathrm{T}_{168^{\prime}}$ and the seventh $\alpha$-helix was extended from amino acid of $A_{176}$ to $Y_{182}$. Ten $\beta$-sheet were found in this protease. The first $\beta$-sheet was extended from amino acid of $\mathrm{T}_{5}$ to $\mathrm{T}_{10^{\prime}}$ the second $\beta$-sheet was extended from amino acid of $G_{13}$ to $D_{18}$, the third $\beta$-sheet was extended from amino acid of $I_{28}$ to $L_{31}$, the fourth $\beta$-sheet was extended from amino acid of $I_{59}$ to $S_{65}$, the fifth $\beta$-sheet was extended from amino acid of $V_{87}$ to $A_{91}$, the sixth $\beta$-sheet was extended from amino acid of $M_{94}$ to $A_{96}$, the seventh $\beta$-sheet was extended from amino acid of $R_{111}$ to $A_{113}$, the eighth $\beta$-sheet was extended from amino acid of $\mathrm{T}_{118}$ to $\mathrm{I}_{121}$, the ninth $\beta$-sheet was extended from amino acid of $\mathrm{G}_{127}$ to $\mathrm{Q}_{129}$, and the tenth $\beta$-sheet was extended from amino acid of $\mathrm{H}_{172}$ to $S_{175}$. The $\beta$-sheets of $\beta-1$ and $\beta-2$ were found to be in the antiparallel position, and this condition was also found in $\beta-8$ and $\beta-10$. Meanwhile, $\beta-3, \beta-4, \beta-5$, and $\beta-7$ were found to be in parallel position. The antiparallel $\beta$-sheets are more stable than parallel $\beta$-sheets as the hydrogen-bonding pattern in the parallel sheet is more optimal (Roeters et al., 2017). The existence of antiparallel position of $\beta$-sheets is therefore required to maintain the structural stability of the barrel form of ClpP_LP. The barrel form of ClpP_LP is functionally important to serve as a degradation containment area. The hydrophobic environment inside the barrel is also functionally required for facilitating the binding to the substrate through hydrophobic interactions.

Figure 10 indicates that the catalytic site of ClpP_LP is highly conserved to the other serine proteases. This indicates that the ClpP_LP utilizes similar catalytic mechanisms to the other serine proteases, where Serine 97 plays a role as a nucleophile. Meanwhile, His122 plays an important role in the deprotonation of Ser97 for nucleophilic formation. The role of His122 is supported by the presence of Asp171, which forms a hydrogen bond with the imidazole ring of His122 so that it is in the proper orientation for deprotonation of Ser97. The presence of Serine amino acids in the catalytic site of this protein makes ClpP_LP classified as a serine-protease group (Li et al., 2013).

In addition, the results of the ClpP_LP intersection of the casein protein substrate using the Peptide Cutter server showed that ClpP_LP only cuts peptide bonds in the amino acid Lysin (K) or Arginine (R), which both amino acids are many found in the casein protein. The process of cutting peptide bonds by ClpP_LP can be seen simply in Fig. 12. The number of amino acids Lysine and Arginine in casein protein is 13 residues, so ClpP_LP will cut the casein substrate at 13 points. These cuttings consist of $\mathrm{K}_{3}, \mathrm{R}_{29^{\prime}} \mathrm{K}_{34^{\prime}}, \mathrm{R}_{37}, \mathrm{~K}_{42^{\prime}}, \mathrm{R}_{55^{\prime}}, \mathrm{R}_{89^{\prime}} \mathrm{K}_{107}, \mathrm{R}_{118^{\prime}}$ $\mathrm{K}_{132^{\prime}} \mathrm{K}_{133^{\prime}}$ and $\mathrm{K}_{137}$

\section{CONCLUSION}

This study showed that the optimization codon approach and synthesis genes could be used in the production of ClpP_LP proteins using inexpensive host cells, E. coli BL21 (DE3). The ClpP_LP produced in this study has a molecular weight of about $25 \mathrm{kDa}$ and showed a real activity against milk casein. Threedimensional structure modeling using the SWISS_ MODEL server showed that this protein is composed of a combination of $7 \alpha$-helix and $10 \beta$-sheets and formed a 14-mer oligomer in the form of a barrel. The active side analysis using Clustal Omega showed that ClpP_LP belongs to the serine protease, with the active side of this protein located at Serine-97, Histidine-122, and Aspartic Acid-171 and only recognizing specific cutting sites on amino acids Lysine (K) or Arginine (R).

\section{CONFLICT OF INTEREST}

The authors (C. Budiman, I. I. Arief, \& C. Sumantri) serve as editorial boards of the Tropical Animal Science Journal, but they have no role in the decision to publish this article. We also certify that no conflict of interest with any financial, personal, or other relationships with other people or organizations related to the material discussed in the manuscript.

\section{ACKNOWLEDGEMENT}

The authors greatly acknowledge the financial assistance provided by the Lembaga Pengelola Dana Pendidikan (LPDP), Ministry of Finance, the Republic of Indonesia in 2016-2018.

\section{REFERENCES}

Afiyah, D. N., I. I. Arief, \& C. Budiman. 2015. Proteolytic characterization of trimmed beef fermented sausages inoculated by Indonesian probiotics: Lactobacillus plantarum IIA2C12 and Lactobacillus acidophilus IIA-2B4. Adv. J. Food. Sci. Technol. 8:27-35. https://doi.org/10.19026/ajfst.8.1459

Arief, I. I., B. S. L. Jenie, M. Astawan, K. Fujiyama, \& A. B. Witarto. 2015. Identification and probiotic characteristics of lactic acid bacteria isolate from Indonesian local beef. Asian J. Anim. Sci. 9:25-36. https://doi.org/10.3923/ ajas.2015.25.36

Arief, I. I., Jakaria, T. Suryati, Z. Wulandari, \& E. Andreas. 
2013. Isolation and characterization of plantaricin produced by Lactobacillus plantarum Strain (IIA-1A5, IIA-1B1, IIA-2B2). Med. Pet. 36:91-100. https://doi.org/10.5398/ medpet.2013.36.2.91

Aruna, K., J. Shah, \& R. Birmole. 2014. Production and partial char-acterization of alkaline protease from Bacillus tequilensis strains CSGAB 0139 isolated from spoilt cottage cheese. Int. J. Appl. Biol. Pharm. 5:201-21.

Ban, E. \& C. R. Picu. 2013. Strength of DNA sticky end links. Biomacromolecules 15:143-149. https://doi.org/10.1021/ bm401425k

Biasini, M., S. Bienert, A. Waterhouse, K. Arnold, G. Studer, T. Schmidt, F. Kiefer, T. Gallo Cassarino, M. Bertoni, \& L. Bordoli. 2014. SWISS-MODEL: modelling protein tertiary and quaternary structure using evolutionary information. Nucleic Acids Res. 42: W252-W258. https://doi. org/10.1093/nar/gku340

Bienert, S., A. Waterhouse, T. A. P. de Beer, G. Tauriello, G. Studer, L. Bordoli, \& T. Schwede. 2017. The SWISSMODEL repository--new features and functionality. Nucleic Acids Res. 45:D313-D319. https://doi.org/10.1093/ nar/gkw1132

Bordoli, L., F. Kiefer, K. Arnold, P. Benkert, J. Battey, \& T. Schwede. 2009. Protein structure homology modeling using SWISS-MODEL workspace. Nat. Protoc. 4:1-13. https:// doi.org/10.1038/nprot.2008.197

Browning, D. F., R. E. Godfrey, K. L. Richards, C. Robinson, \& S. J. W. Busby. 2019. Exploitation of the Escherichia coli lac operon promoter for controlled recombinant protein production. Biochem. Soc. Trans. 47:755-763. https://doi. org/10.1042/BST20190059

Budiman, C., I. I. Arief, F. Opook, \& M. Yusuf. 2021. A meatderived lactic acid bacteria, Lactobacillus plantarum IIA, expresses a functional parvulin-like protein with unique structural property. Online J. Biol. Sci. 21:120-135. https:// doi.org/10.3844/ojbsci.2021.120.135

Camacho, C., G. Coulouris, V.Avagyan, N. Ma, J. Papadopoulos, K. Bealer, \& T. L. Madden. 2009. BLAST+: architecture and applications. BMC Bioinformatics. 10, 421. https://doi. org/10.1186/1471-2105-10-421

Cardoso, V. M., G. Campani, M. P. Santos, G. G. Silva, M. C. Pires, V. M. Gonçalves, R. de C. Giordano, C. R. Sargo, A. C. L. Horta, \& T. C. Zangirolami. 2020. Cost analysis based on bioreactor cultivation conditions: Production of a soluble recombinant protein using Escherichia coli BL21(DE3). Biotechnol. Rep. 26:1-13. https://doi.org/10.1016/j. btre.2020.e00441

Fatmarani, R., I. I. Arief, \& C. Budiman. 2018. Purification of bacteriocin from Lactobacillus plantarum IIA-1A5 grown in various whey cheese media under freeze dried condition. Trop. Anim. Sci. J. 41:191-199. https://doi.org/10.5398/ tasj.2018.41.1.53

Fiege, K., \& N. F. Dinkel. 2020. Construction of a new T7 promoter compatible Escherichia coli Nissle 1917 strain for recombinant production of heme dependent proteins. Microb. Cell Fact. 19:190. https://doi.org/10.1186/ s12934-020-01447-5

Florentin, A., D. R. Stephens, C. F. Brooks, R. P. Baptista, \& V. Muralidharan. 2020. Plastid biogenesis in malaria parasites requires the interactions and catalytic activity of the Clp proteolytic system. PNAS. https://doi.org/10.1073/ pnas.1919501117

Frees, D., U. Gerth, \& H. Ingmer. 2014. Clp chaperones and proteases are central in stress survival, virulence and antibiotic resistance of Staphylococcus aureus. Int. J. Med. Microbiol. 304:142-149. https://doi.org/10.1016/j.ijmm.2013.11.009

Fu, H., Y. Liang, X. Zhong, Z. Pan, L. Huang, H. Zhang, Y. Xu, W. Zhou, \& Z. Liu. 2020. Codon optimization with deep learning to enhance protein. Sci. Rep. 10: Article number
17617. https://doi.org/10.1038/s41598-020-74091-z

Gaspar, P., J. L. Oliveira, J. Frommlet, M. A. Santos, \& G. Moura. 2012. EuGene: maximizing synthetic gene design for heterologous expression. Bioinformatics 28:683-2684. https://doi.org/10.1093/bioinformatics/bts465

Gurung, N., S. Ray, S. Bose, \& V. Rai. 2013. A broader view: Microbial enzymes and their relevance in industries, medicine, and beyond. Biomed Res. Int. 2013:1-18. https://doi. org/10.1155/2013/329121

Haddad, Y., V. Adam, \& Z. Heger. 2020. Ten quick tips for homology modeling of highresolution protein 3D structures. Plos Comput. Biol. 16:e1007449. https://doi.org/10.1371/ journal.pcbi.1007449

Hughes, R.A., A. E. Miklos, \& A. D. Ellington. 2011. Gene synthesis: methods and applications. Methods Enzymol. 498:277309. https://doi.org/10.1016/B978-0-12-385120-8.00012-7

Kang, Y. S., J. A. Song, K. Y. Han, \& J. Lee. 2015. Escherichia coli EDA is a novel fusion expression partner to improve solubility of aggregation-prone heterologous proteins. J. Biotechnol. 194:39-47. https://doi.org/10.1016/j. jbiotec.2014.11.025

Kuhlman, B. \& P. Bradley. 2019. Advances in protein structure prediction and design. Nat. Rev. Mol. Cell Biol. 20:681-697. https://doi.org/10.1038/s41580-019-0163-x

Lee, B. G., M. K. Kim, \& H. K. Song. 2011. Structural insights into the conformational diversity of ClpP from Bacillus subtilis. Mol. Cells. 32:589-595. https://doi.org/10.1007/ s10059-011-0197-1

Li, Q., L, Yi, P. Marek, \& B. L. Iverson. 2013. Commercial proteases: Present and future. FEBS Lett. 587:1155-1163. https:// doi.org/10.1016/j.febslet.2012.12.019

Liu, B., Q. Kong, D. Zhang, \& L. Yan. 2018. Codon optimization significantly enhanced the expression of human $37-\mathrm{kDa}$ iLRP in Escherichia coli. 3 Biotech 8:Article number 210. https://doi.org/10.1007/s13205-018-1234-y

Mauro, V. P. 2018. Codon optimization in the production of recombinant biotherapeutics: Potential risks and considerations. BioDrugs 32:69-81. https://doi.org/10.1007/ s40259-018-0261-x

Miguel, Â. S. M., T. S. Martins-Meyer, E. Veríssimo da Costa Figue-iredo, B. W. P. Lobo, \& G. M. Dellamora-Ortiz. 2013. Enzymes in bakery: Current and future trends. In: Muzzalupo I (Eds). Food Industry. InTech, Rijeka, Croatia.

Murwantoko., C. K. Fusianto, \& Triyanto. 2016. Gene cloning and protein expression of koi herpesvirus ORF25. Hayati 23:143-149. https://doi.org/10.1016/j.hjb.2016.10.001

Newman, M., T. Strzelecka, L. F. Dorner, Schildkraut, \& A. K. Aggarwal. 1994. Structure of endonuclease BamH1 and its relationship to EcoR1. Nature 368:660-664. https://doi. org/10.1038/368660a0

Nigam, P. S. 2013. Microbial enzymes with special characteristics for biotechnological applications. Biomolecules 3:597611. https://doi.org/10.3390/biom3030597

Rahimzadeh, M., M. Sadeghizadeh, F. Najafi, S. S. Arab, \& H. Mobasheri. 2016. Impact of heat shock step on bacterial transformation efficiency. Mol. Biol. Res. Commun. 5:257-261.

Rahmen, N., C. D. Schlupp, H. Mitsunaga, A. Fulton, T. Aryani, L. Esch, U. Schaffrath, E. Fukuzaki, K. E. Jaeger, \& J. Büchs. 2015. A particular silent codon exchange in a recombinant gene greatly influences host cell metabolic activity. Microb. Cell. Fact. 14:156. https://doi.org/10.1186/ s12934-015-0348-8

Ramirez, O., R. Zamora, G. Espinosa, E. Merino, F. Bolivar, \& R. Quintero. 1994. Kinetic study of penicillin acylase production by recombinant $E$. coli in batch cultures. Process Biochem. 29:197-206. https://doi. org/10.1016/0032-9592(94)85004-6

Raveendran, S., B. Parameswaran, S. B. Ummalyma, A. 
Abraham, A. K. Mathew, A. Madhavan, S. Rebello, \& A. Pandey. 2018. Applications of microbial enzymesin food industry. Food Technol. Biotechnol. 56:16-30. https://doi. org/10.17113/ftb.56.01.18.5491

Razali, R., C. Budiman, K. A. Kamaruzaman, \& V. K. Subbiah. 2021. Soluble expression and catalytic properties of codon-optimized recombinant bromelain from MD2 pineapple in Escherichia coli. Protein J. 40:406-418. https://doi. org/10.1007/s10930-021-09974-9

Rehan, F., N. Ahemada, \& M. Gupta. 2019. Casein nanomicelle as an emerging biomaterial-A comprehensive review. Colloids Surf. B: Biointerfaces. 179:280-292. https://doi. org/10.1016/j.colsurfb.2019.03.051

Remmert, M., A. Biegert, A. Hauser, \& J. Soding. 2011. HHblits: lightning-fast iterative protein sequence searching by HMM-HMM alignment. Nat. Methods. 9:173-175. https:// doi.org/10.1038/nmeth.1818

Roeters, S. J., A. Iyer, G. Pletikapić, V. Kogan, V. Subramaniam, \& S. Woutersen. 2017. Evidence for intramolecular antiparallel beta-sheet structure in alpha-synuclein fibrils from a combination of two-dimensional infrared spectroscopy and atomic force microscopy. Sci. Rep. 7:4105. https://doi. org $/ 10.1038 /$ srep41051

Rohin, M. A. K., A. Bakar, C. Abdullah, \& A. M. Ali. 2012. Antibacterial activity of flesh and peel methanol fractions of red pitaya, white pitaya and papaya on selected food microorganisms. Int. J. Pharm. Pharm. Sci. 4:185-190.

Rosano, G. L., \& E. A. Ceccarelli. 2014. Recombinant protein expression in Escherichia coli: advances and challenges. Front.
Microbiol. 5:172. https://doi.org/10.3389/fmicb.2014.00172

Shin, W. H., X. Kang, J. Zhang, \& D. Kihara. 2017. Prediction of local quality of protein structure models considering spatial neighbors in graphical models. Sci. Rep. 7:40629. https://doi.org/10.1038/srep40629

Singh, R., A. Mittal, M. Kumar, \& P. K. Mehta. 2016. Microbial proteases in commercial applications. J. Pharm. Chem. Biol. Sci. 4:365-374.

Singh, R., M. Kumar, A. Mittal, \& P. K. Mehta. 2016. Microbial enzymes: Industrial progress in 21st century. 3 Biotech 6:174. https://doi.org/10.1007/s13205-016-0485-8

Sulthoniyah, S. T. M., Hardoko, \& H. Nursyam. 2015. Characterization of extracellular protease lactic acid bacteria from shrimp paste. J. Life Sci. Biomed. 5:01-05.

Waterhouse, A., M. Bertoni, S. Bienert, G. Studer, G. Tauriello, R. Gumienny, F. T. Heer, T.A.P. de Beer, C. Rempfer, L. Bordoli, R. Lepore, \& T. Schwede. 2018. SWISS- MODEL: homology modelling of protein structures and complexes. Nucleic Acids Res. 46:W296-W303. https://doi.org/10.1093/ nar/gky 427

Watson, R. J., I. Schildkraut, B. Q. Qiang, S. M. Martin, \& L. P. Visentin. 1982. NdeI: A restriction endonuclease from Neisseria denitrificans which cleaves DNA at 5'-CATATG-3' sequences. Febs letters. 150:114-116. https:// doi.org/10.1016/0014-5793(82)81315-X

Yaraguppi, D. A., B. B. Udapudi, L. R. Patil, V. S. Hombalimath, \& A. R. Shet. 2012. In-silico analysis for predicting protein ligand interaction for snake venom protein. J. Adv. Bioinforma. Appl. Res. 3:345-356. 